\title{
Investigation of Skewing Effects on the Vibration Reduction of Three-Phase Switched Reluctance Motors
}

\author{
Chun $\mathrm{Gan}^{1}$, Jianhua $\mathrm{Wu}^{1}$, Mengjie Shen ${ }^{1}$, Shiyou Yang ${ }^{1}$, Yihua $\mathrm{Hu}^{1,2}$, and Wenping $\mathrm{Cao}^{3,4}$ \\ ${ }^{1}$ College of Electrical Engineering, Zhejiang University, Hangzhou 310027, China \\ ${ }^{2}$ Department of Electronic and Electrical Engineering, University of Strathclyde, Glasgow, G1 1XQ UK \\ ${ }^{3}$ School of Electronics, Electrical Engineering and Computer Science, Queen's University Belfast, BT9 5AH UK \\ ${ }^{4}$ Department of Electrical Engineering and Computer Science, Massachusetts Institute of Technology, \\ Cambridge, MA 02139 USA
}

\begin{abstract}
Switched reluctance motors (SRMs) are gaining in popularity because of their robustness, cheapness and excellent highspeed characteristics. However, they are known to cause vibration and noise primarily due to the radial pulsating force resulting from their double-saliency structure. This paper investigates the effect of skewing the stator or/and rotor on the vibration reduction of the three-phase SRMs by developing four 12/8-pole SRMs including a conventional SRM, a skewed rotor-SRM (SR-SRM), a skewed stator-SRM (SS-SRM), and a skewed stator and rotor-SRM (SSR-SRM). The radial force distributed on the stator yoke under different skewing angles is extensively studied by the finite element method (FEM) and experimental tests on the four prototypes. The inductance and torque characteristics of the four motors are also compared and a control strategy by modulating the turn-on and turn-off angles for SR-SRM and SS-SRM are also presented. Furthermore, experimental results have validated the numerical models and the effectiveness of the skewing in reducing the motor vibration. Test results also suggest that skewing the stator is more effective than skewing the rotor in SRMs.
\end{abstract}

Index Terms -Finite element method (FEM), radial force, skewing, switched reluctance motors (SRMs), vibration.

\section{INTRODUCTION}

$\mathrm{O}$ VER the last three decades, switched reluctance motors (SRMs) have attracted much attention for research and industrial applications, due to their rare-earth-free feature, low cost, high efficiency, and robust structure [1]-[3], making them especially suited for high-temperature and high-speed operations. However, because of their double-saliency structure, vibration and noise are the inherent issues caused by normal force fluctuations during phase current excitations [4], [5], which pose a drawback for the motors in noise sensitive applications. In these machines, the attraction force can be divided into tangential and radial components relative to the rotor. The tangential force is converted into the rotational torque, and the radial force contributes to vibration and acoustic noise [6]-[9].

In order to reduce the vibration of the SRM, some advanced technologies have been proposed, mainly following three routes: 1) accurate calculations and predictions of radial force; 2) development of the radial force control strategies; 3) design of improved motor structures.

In [8], the origin of vibration in 8/6-pole SRMs is investigated, and a new method for prediction of vibration is proposed. In [9], a fast and precise method is developed for predicting acoustic noise, based on the spectrum distribution of radial vibration measured on the stator frame. The vibration and noise characteristics of 12/8-pole and 6/4-pole SRMs are compared and investigated in [10], which shows a more reduced radial vibration force and less deformation in 12/8pole SRM.

Manuscript received March 5, 2015; accepted May 27, 2015. Corresponding author: J. Wu, College of Electrical Engineering, Zhejiang University, Hangzhou, China (e-mail: hzjhwu@163.com).

Digital Object Identifier (inserted by IEEE).
Several other methods are focused on the control strategies to reduce the radial force for SRMs. A scheme that produces a controlled radial force for a 12/8-pole SRM is proposed in [11] by controlling all pole currents independently. In [12], the average torque and radial force are independently controlled in a bearingless SRM. In [13], a hybrid excitation method with a C-dump converter is proposed to reduce the radial vibration force and acoustic noise for SRM. A two-stage commutation strategy is employed in [14], [15] for the same purposes.

However, the radial force control strategies cannot be adopted for various operational conditions and speed control schemes, and the radial force cannot be completely eliminated. Considering this point, some new technologies are proposed to improve the motor structure. A low-noise SRM is designed in [16], by exchanging the commonly used slot wedges with structural stator spacers which are made of a ceramic material. The reduction of vibration and acoustic noise in SRM is investigated in [17] by a comprehensive analysis of the material and structure of the stator frame in relation to the SRM vibrations. In [18], a doubly salient permanent-magnet motor which resembles the structure of an SRM, using a skewed rotor is proposed and designed to minimize the cogging torque. A linear SRM with skewed stator [19] and a single-phase SRM with skewed stator and rotor [20] are proposed to reduce the acoustic noise and vibration, by analyzing the radial force distribution on the stator yoke. However, the detailed comparisons between the motors equipped with the skewed teeth in the stator, rotor, or both, are not presented and investigated. In [21], two novel SRMs with a stepped rotor and a skewed rotor are introduced and compared in terms of their fault diagnosis indices.

This paper investigates the radial force distributed on the stator yoke by developing four 12/8-pole SRMs, which are conventional SRM, skewed rotor-SRM (SR-SRM), skewed 
stator-SRM (SS-SRM), and skewed stator and rotor-SRM (SSR-SRM). The radial forces distributed on the stator yoke under different skewing angles are investigated by a three-dimensional (3-D) finite element method (FEM) in Ansoft. The inductance and torque characteristics of the different motor structures are also compared. The three novel motors with $22.5^{\circ}$ skewing angle and a conventional SRM are all fabricated for experimental validation tests. The vibration signals are tested by installing an acceleration sensor on the stator frame. Furthermore, the torque and efficiency of the four prototype motors are compared in details. The simulation and experimental tests are carried out to confirm the effectiveness of skewing in SRMs.

This paper is organized as follows. Section II presents the skewed teeth and the radial force model for the different motors. In Section III, the radial force of the motors is analyzed and compared in details by FEM. The numerical models are verified by the experimental results in Section IV. Finally, conclusions are given in Section V.

\section{SKewed TEETH Shapes AND RAdial Force}

This section evaluates the effect of skewing the stator or/ and rotor of SRMs on the radial pulsating force.

\section{A. Structure of a Three-Phase 12/8-pole SRM}

The structure and attraction force of a three-phase 12/8-pole SRM are shown in Fig. 1 [10]. As illustrated in the figure, windings $A_{1}, A_{2}, A_{3}$, and $A_{4}$ are connected in series to form the phase $\mathrm{A}$ winding, and the four phase currents are controlled independently. The mechanical angle of the rotor unaligned position and aligned position are defined as $0^{\circ}$ and $22.5^{\circ}$, respectively. When a current is conducted in the phase winding, the attraction force relative to the rotor can be divided into tangential force and radial force. The tangential force contributes to the torque for rotor rotation, whilst the radial force contributes to the vibration relative to the stator yoke.

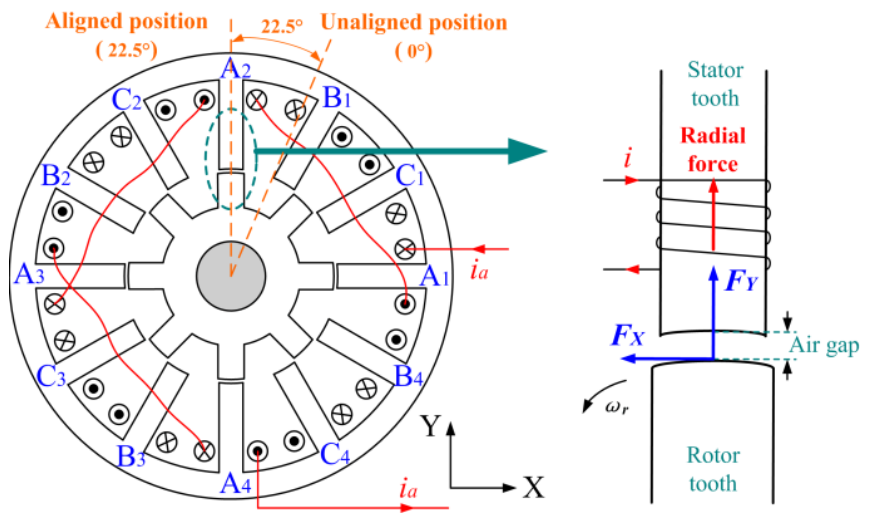

Fig. 1. Schematic and attraction force of the 12/8-pole SRM.

\section{B. Motor Structures with Skewed Teeth}

In this paper, three motors with different skewing techniques (stator-skewed, rotor-skewed, and both skewed) are designed, in comparison of a standard SRM (unskewed). The four motors are shown in Fig. 2. As illustrated in the figure, the conventional SRM is obtained by assembling the normal stator and normal rotor; the SR-SRM is obtained by assembling the normal stator and skewed rotor; the SS-SRM is obtained by assembling the skewed stator and normal rotor; and the SSR-SRM is obtained by assembling the skewed stator and skewed rotor.

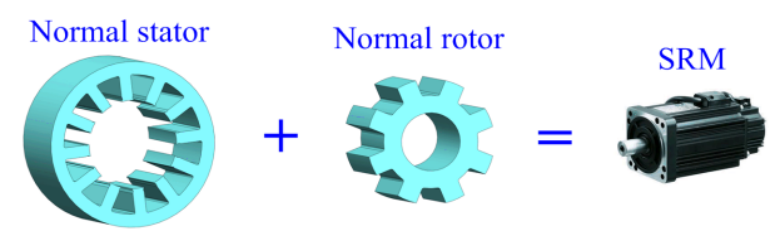

(a)

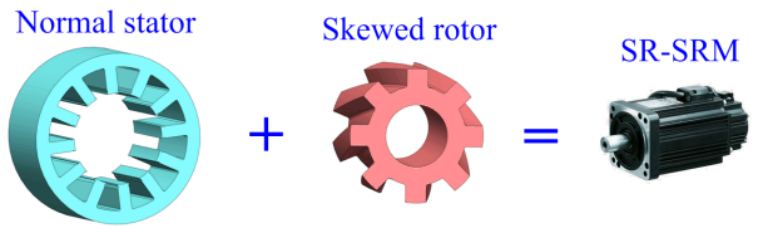

(b)

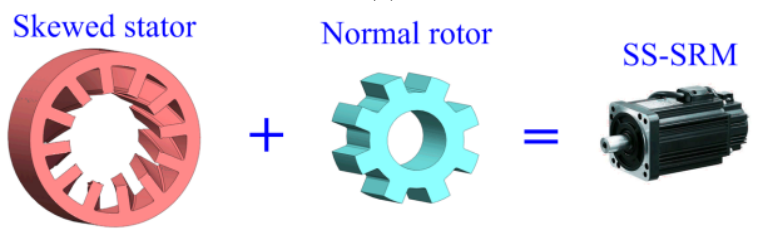

(c)

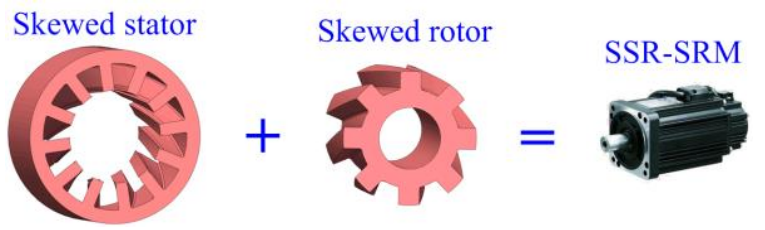

(d)

Fig. 2. Four SRM structures. (a) Conventional SRM. (b) SR-SRM. (c) SSSRM. (d) SSR-SRM.

Fig. 3(a) and (b) show the definition of the skewing angle in terms of the stator and rotor teeth. The skewing angle for the stator teeth, $\theta_{s s}$, is defined as the arc angle of the stator teeth projection on the inner circle. Similarly, the skewing angle for the rotor teeth, $\theta_{s r}$, is defined as the arc angle of the rotor teeth projection on the outer circle. In order to calculate these angles, a schematic diagram is demonstrated for the angle calculation in Fig. 4.

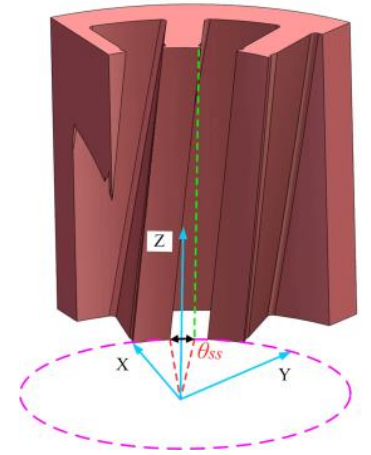

(a)

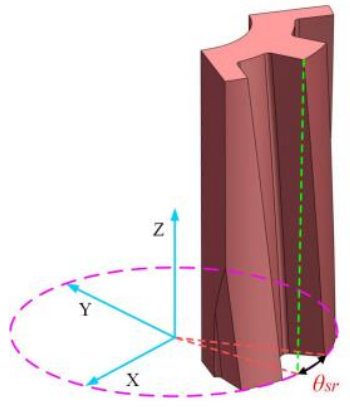

(b)
Fig. 3. Definition of the skewing angle. (a) Stator. (b) Rotor. 


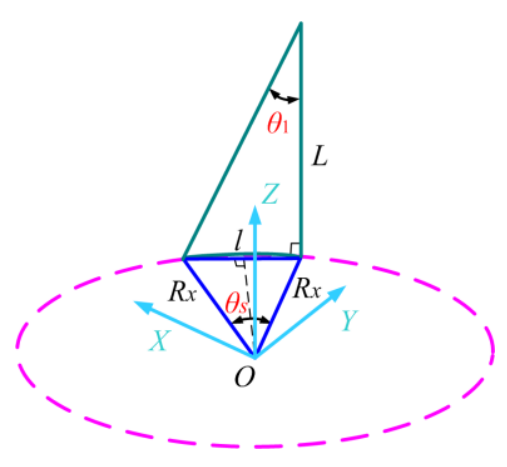

Fig. 4. 3-D diagram for the skewed angle.

As illustrated in Fig. 4, the skewing angles for the stator and rotor teeth are given by

$$
\theta_{s}=\frac{180 \times l}{\pi R_{x}}\left(R_{x}=\frac{D_{s i}}{2}, \frac{D_{r o}}{2} ; \theta_{s}=\theta_{s s}, \theta_{s r}\right)
$$

where $l$ is the projected arc length, $R_{x}$ is the stator inner radius or rotor outer radius, and $D_{s i}$ and $D_{r o}$ are the stator inner diameter and rotor outer diameter, respectively.

The relationship between $\theta_{1}$ and $\theta_{s}$ can be expressed as

$$
L \tan \theta_{1}=2 R_{x} \sin \frac{\theta_{s}}{2}
$$

where $L$ is the core length, and $\theta_{1}$ is the angle between the skewed teeth and the $z$-axis.

\section{Radial Force Model}

The derivation of the mathematical force model is based on the Maxwell stress tensor in this paper. According to the Maxwell stress method, the total force is expressed as [19]

$$
F=\int_{s} T d s
$$

where $s$ is the integral surface of a selected element, and $T$ is the Maxwell stress tensor, which is given by

$$
T=\frac{1}{\mu_{0}}\left[(B \cdot \vec{n}) B-\frac{1}{2} \nabla B^{2} \vec{n}\right]
$$

where $\mu_{0}$ is the relative permeability of vacuum, $B$ is the magnetic intensity, and $n$ is the normal vector of the vertical direction.

The tangential force density and radial force density in the air gap can be expressed as

$$
\begin{gathered}
f_{t}=\frac{1}{2 \mu_{0}} 2 B_{r} B_{t} \\
f_{r}=\frac{1}{2 \mu_{0}}\left(B_{r}^{2}-B_{t}^{2}\right)
\end{gathered}
$$

where $f_{t}$ and $f_{r}$ are the tangential and radial force densities, respectively; and $B_{t}$ and $B_{r}$ are the tangential and radial magnetic intensities from the tangential direction and vertical direction, respectively.

From Eqs (5) and (6), the tangential force and radial force in an integral surface can be found by

$$
\begin{gathered}
F_{t}=\int_{s} f_{t} d s=\frac{1}{\mu_{0}} \int_{s} B_{r} B_{t} d s \\
F_{r}=\int_{s} f_{r} d s=\frac{1}{2 \mu_{0}} \int_{s}\left(B_{r}^{2}-B_{t}^{2}\right) d s
\end{gathered}
$$

The torque acting on the rotor pole, as shown in Fig. 1, can be written as

$$
T_{t}=F_{t} \frac{D_{r o}}{2}=\frac{D_{r o}}{2} \int_{s} f_{t} d s=\frac{D_{r o}}{2 \mu_{0}} \int_{s} B_{r} B_{t} d s
$$

\section{Radial Force on the Stator Yoke}

In order to analyze the radial force distribution, a part of the stator yoke should be selected and divided into small elements for investigation [20].

A stator pole pitch, i.e., the mechanical separation between adjacent stator teeth of the three-phase 12/8-pole SRM, is calculated by

$$
\beta_{s p}=\frac{360^{\circ}}{N_{s}}=\frac{360^{\circ}}{12}=30^{\circ}
$$

where $N_{s}$ is the number of the stator poles.

Considering the symmetric structure of the motor, a stator pole pitch needs to be selected to analyze the radial force distributed on the stator yoke. As shown in Fig. 5, the selected yoke for $30^{\circ}$ is divided into ten elements of $3^{\circ}$ each, and the middle elements ( 3 and 4 ) are aligned with the central axis of the stator tooth.

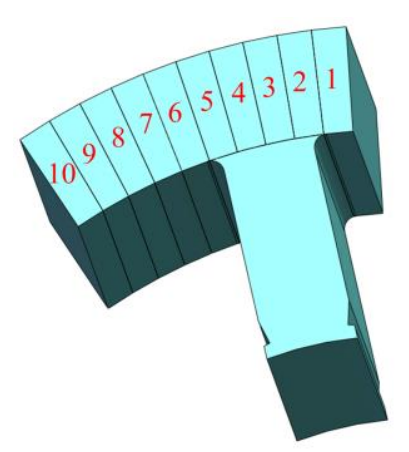

(a)

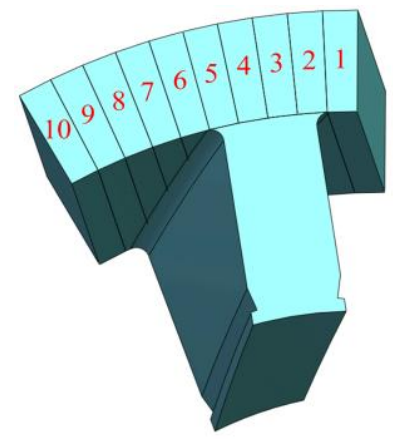

(b)
Fig. 5. Division of the stator yoke for radial force analysis. (a) Conventional stator. (b) Skewed stator.

In Fig. 4, the line density of the radial force is expressed as

$$
\rho=F_{r} \cdot \frac{\cos \theta_{1}}{L}=\frac{F_{r}}{L} \cdot \frac{1}{\sqrt{\tan ^{2} \theta_{1}+1}}
$$

According to (2), Eq (11) can be further represented by

$$
\rho=\frac{F_{r}}{L} \cdot \frac{1}{\sqrt{\left(\frac{2 R_{x}}{L} \sin \frac{\theta_{s}}{2}\right)^{2}+1}}
$$

From (12), $\rho$ decreases as the skewing angle increases. Thus, the radial force can be smoothed out by proper teeth skewing. 


\section{3-D FinITE ELEMENT SiMULATION}

In this paper, the developed motors are simulated in Ansoft FEM environment, and the 3-D FEM simulation models are established for this investigation. The design specifications for the SRM are shown in Table I. The dimensions and ratings of the conventional SRM, novel SR-SRM, novel SS-SRM and novel SSR-SRM are the same for the comparative study. The only differences between these four configurations are their skewing features. Fig. 6 shows the 3-D finite element simulation model and the corresponding symbols of the prototype three-phase 12/8-pole SRM.

TABLE I

MOTOR PARAMETERS

\begin{tabular}{ccc}
\hline \hline Parameter & Symbol & Value \\
\hline Phase number & $m$ & 3 \\
Stator/rotor poles & $N_{s} / N_{r}$ & $12 / 8$ \\
Rated power (W) & $P_{n}$ & 150 \\
Rated load (N.m) & $T_{n}$ & 0.95 \\
Rated speed (r/min) & $n_{r}$ & 1500 \\
Stator outer diameter (mm) & $D_{s o}$ & 102 \\
Stator inner diameter (mm) & $D_{s i}$ & 54.5 \\
Rotor outer diameter (mm) & $D_{r o}$ & 54 \\
Rotor inner diameter (mm) & $D_{r i}$ & 25 \\
Core length (mm) & $L$ & 58 \\
Number of turns & $N$ & 100 \\
Stator pole length (mm) & $l_{s p}$ & 15.75 \\
Stator yoke length (mm) & $l_{s y}$ & 8 \\
Rotor pole length (mm) & $l_{r p}$ & 7 \\
Rotor yoke length (mm) & $l_{r y}$ & 7.5 \\
Air gap length (mm) & $l_{g}$ & 0.25 \\
Stator pole arc $(\mathrm{deg})$ & $\beta_{s}$ & 15 \\
Rotor pole arc (deg) & $\beta_{r}$ & 18 \\
Skewing angles & $\theta_{s}$ & $0^{\circ} / 7.5^{\circ} / 11.25^{\circ}$ \\
& & $/ 15^{\circ} / 22.5^{\circ}$ \\
\hline \hline
\end{tabular}

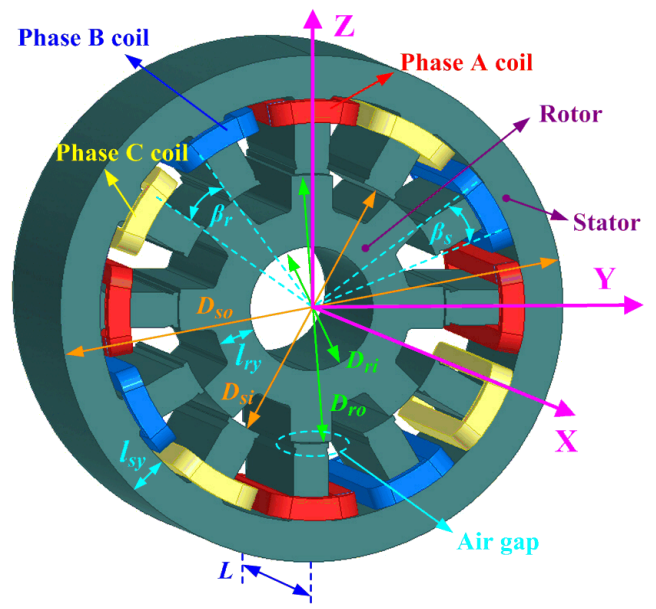

Fig. 6. 3-D finite element simulation model for 12/8-pole SRM.

Fig. 7 shows the comparisons of the radial force in the conventional SRM, SR-SRM, SS-SRM, and SSR-SRM with different skewing angles. The skewing angles of the motors are selected as $7.5^{\circ}, 11.25^{\circ}, 15^{\circ}$, and $22.5^{\circ}$, respectively, for investigation. The motors are simulated in the same operations, at the rotor aligned position of phase $\mathrm{A}$, with a $1.5 \mathrm{~A}$ phase current. As shown in Fig. 7(a), when the rotor is skewed with different angles, the radial force varies with respect to different elements. The force reaches its positive peak at elements 3 and 4, and its negative peak at elements 1 and 6 . However, the force is reduced gradually when the skewed angle increases from $0^{\circ}$ to $22.5^{\circ}$. Fig. 7(b) shows the skewed stator condition. The peak values move along with the element number increased, when the skewing angle varies from $0^{\circ}$ to $22.5^{\circ}$. The radial force distributed on the stator yoke are much smaller at the $22.5^{\circ}$ angle, compared to other angles, which can reduce the stator vibration and deformation. Fig. 7(c) shows the skewing angle for the SSR-SRM. The radial force is also reduced at $22.5^{\circ}$, which is similar to the force distribution in the SS-SRM.

Considering that the radial forces of the SR-SRM, SS-SRM, and SSR-SRM are all reduced as the skewing angle increases, the radial forces of the three motors for the $22.5^{\circ}$ skewing angle are obtained and shown in Fig. 8. The SS-SRM and SSR-SRM both have much reduced radial force, compared to the SR-SRM. However, the force distributions are very similar between the SS-SRM and SSR-SRM.

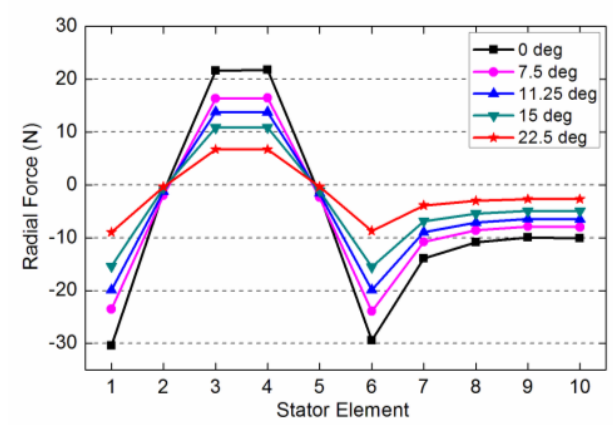

(a)

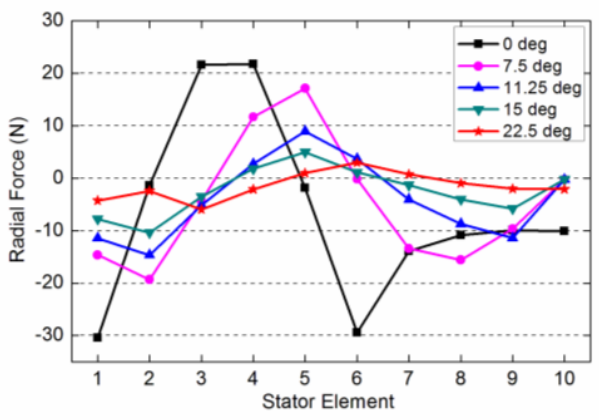

(b)

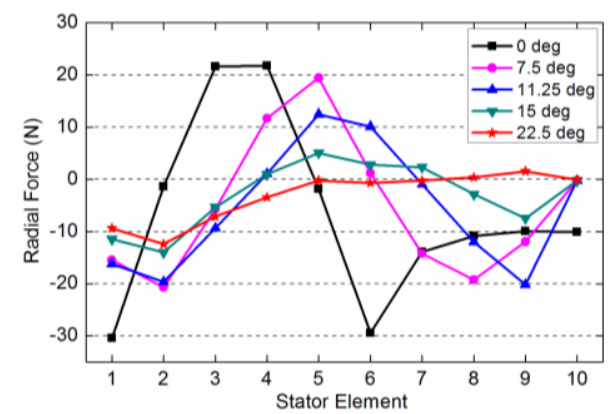

(c)

Fig. 7. Radial force as a function of the skewing angle. (a) SR-SRM. (b) SSSRM. (c) SSR-SRM. 


\section{IEEE TRANSACTIONS ON MAGNETICS}

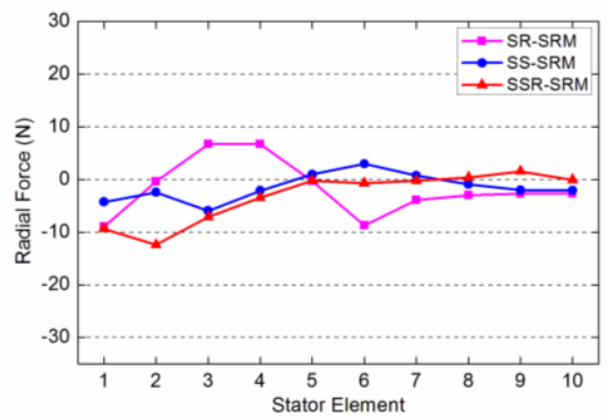

Fig. 8. Radial force for the SR-SRM, SS-SRM, and SSR-SRM $\left(22.5^{\circ}\right.$ skewing angle).

The transient radial force distribution at different rotor positions can be seen in Fig. 9, where $F_{r 1} \sim F_{r 10}$ are the radial force on the divided elements 1 10, respectively. The maximum radial force of the SR-SRM, SS-SRM and SSRSRM are all reduced compared to the conventional one, although the rotor position for the maximum force may be different. The SS-SRM and SSR-SRM both have the significant reduced radial force, which also agrees with the analytical results in Fig. 8.

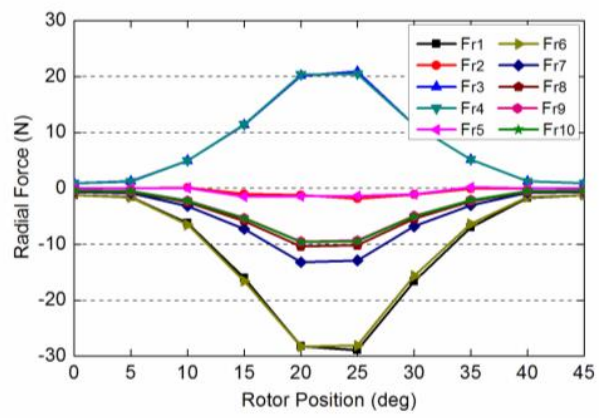

(a)

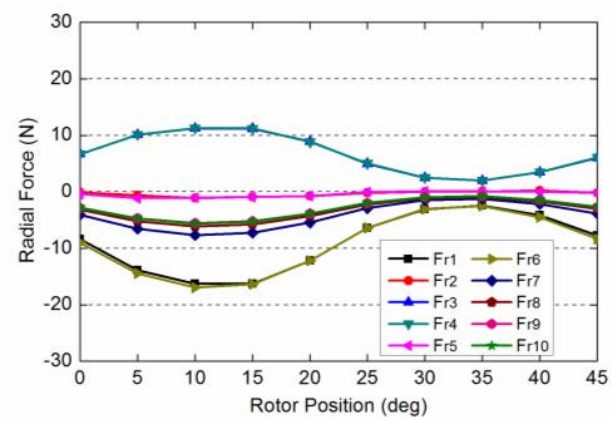

(b)

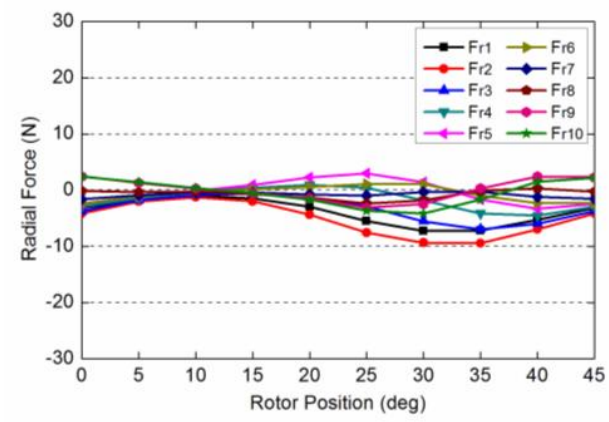

(c)

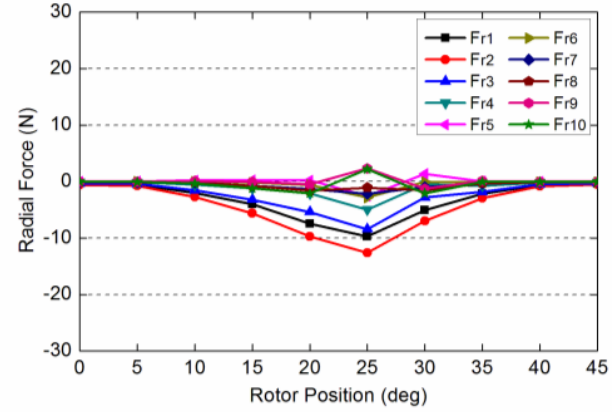

(d)

Fig. 9. Transient radial force distribution at different rotor positions. (a) Conventional SRM. (b) SR-SRM (22.5 skewing angle). (c) SS-SRM (22.5 skewing angle). (d) SSR-SRM (22.5 $5^{\circ}$ skewing angle).

Fig. 10 shows comparisons of the static inductance and torque between the conventional SRM, SR-SRM, SS-SRM, and SSR-SRM, in the case of $22.5^{\circ}$ skewing angle. As shown in Fig. 10(a), the inductance profile of the SS-SRM and SRSRM changes more significantly than the conventional SRM. The inductance of SSR-SRM decreases slightly at the rotor positions of $15^{\circ}$ and $20^{\circ}$; and increases slightly at $30^{\circ}$ while other angular points match well with the traditional one. The inductance phases of the SR-SRM and SS-SRM are a leading $10.5^{\circ}$ and a lagging $10.5^{\circ}$, respectively. In Fig. 10(b), compared to the conventional SRM, the torque decreases remarkably for SR-SRM, and slightly for SS-SRM, which again match well with the SSR-SRM. However, the decreased torque will lead to the efficiency reduction. As illustrated in the figure, the torque phases of the SR-SRM and SS-SRM are advanced for $10.5^{\circ}$ and lagged for $10.5^{\circ}$, respectively. In order to ensure that the current conducts in the same torque region in accordance with the conventional SRM, the turn-on and turnoff angles of stator currents should be set as a leading $10.5^{\circ}$ for SR-SRM, and a lagging $10.5^{\circ}$ for SS-SRM, compared to the conventional SRM.

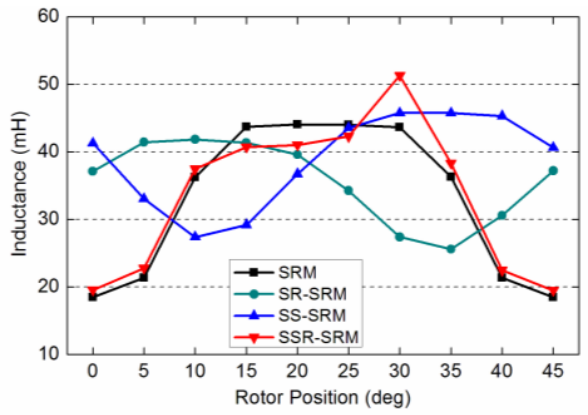

(a)

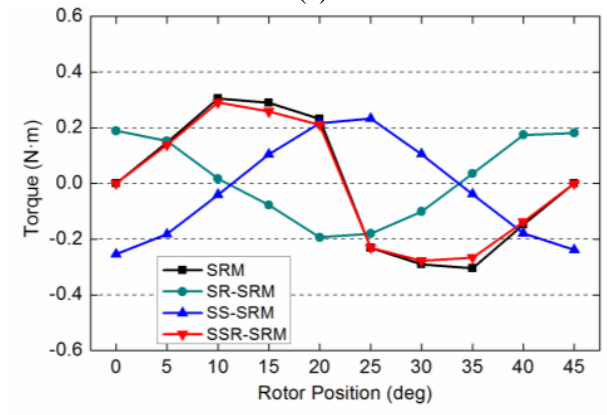

(b)

Fig. 10. Static inductance and torque for the SRM, SR-SRM, SS-SRM, and SSR-SRM. (a) Inductance. (b) Torque 
Fig. 11 shows the magnetic flux density for SRM and SSRSRM with the stator and rotor both skewed $22.5^{\circ}$, at the aligned position of phase A. These distributions are obtained by a dc current excitation of $1.5 \mathrm{~A}$ in phase $\mathrm{A}$ winding. It can be observed that the flux densities in the excited stator poles and aligned rotor poles are much higher than the other stator and rotor poles. The flux lines in SRM and SSR-SRM cross the air gap to the rotor and complete their path through the adjacent pole winding back into the stator, and they are intensified along the shortest path through the stator teeth, as shown in Fig. 12.

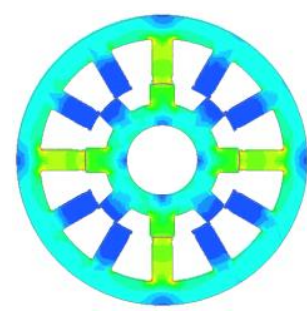

(a)

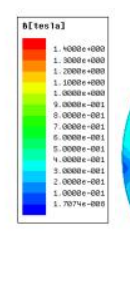

(b)

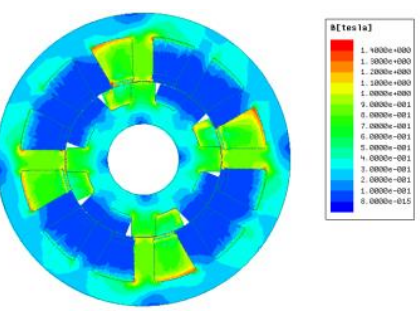

Fig. 11. Magnetic flux density. (a) SRM. (b) SSR-SRM $\left(22.5^{\circ}\right.$ skewing angle).

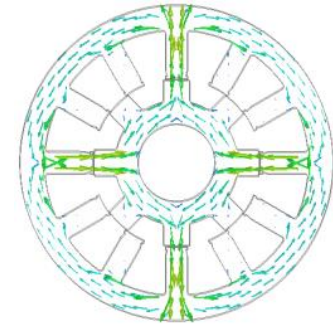

(a)

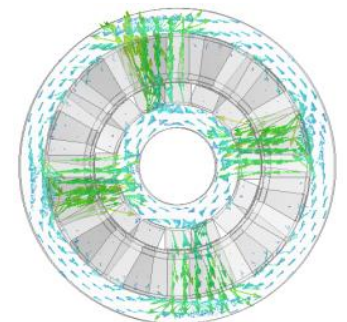

(b)
Fig. 12. Flux lines distribution. (a) SRM. (b) SSR-SRM $\left(22.5^{\circ}\right.$ skewing angle).

\section{EXPERIMENTAL RESULTS}

In order to compare the performance of these SRMs, four motors including the conventional SRM and $22.5^{\circ}$ skewed SRSRM, SS-SRM and SSR-SRM are all designed and prototyped for experimental validation, by assembling the different stators and rotors. In reality, there only need two stators and two rotors (see Fig. 13) to achieve the combination of four motors. An experimental setup is developed for tests and the schematic diagram of its control system is shown in Fig. 14. In the experiments, the SRMs are powered by an adjustable $120-\mathrm{V}$ dc power supply. A dSPACE-DS1006 control board is employed as the main controller to generate the drive signals. An asymmetric half-bridge converter is employed to drive the motor. The phase currents are measured by the Hall-effect current sensors (LA-55P) and processed by a multi-channel analog to digital (A/D) converter for current regulation control. The rotor position is obtained by using an incremental encoder with 2500 lines. In the schematic diagram, the outer loop is a motor speed controller, which reads the rotor angular position and calculates the motor speed for the closed-loop control. A current hysteresis control scheme is developed to make up a current controller, and a proportional integral (PI) algorithm is used to give the current reference to regulate the motor speed.
An acceleration sensor is installed on each stator frame to measure the vibration signal.

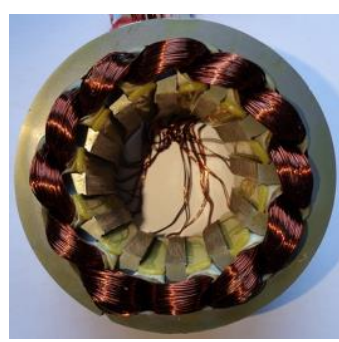

(a)

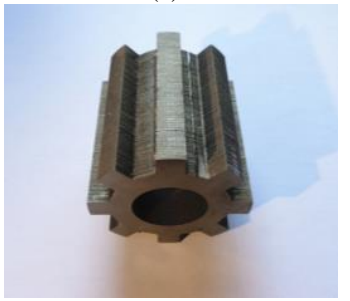

(c)

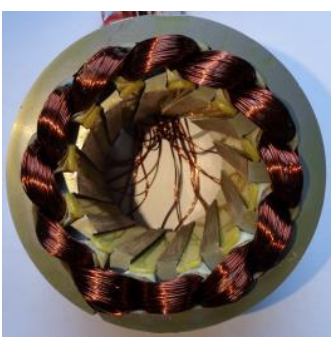

(b)

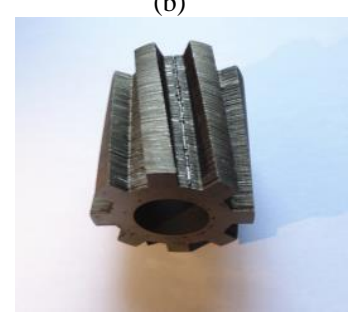

(d)
Fig. 13. Prototypes of the stators and rotors. (a) Normal stator. (b) Skewed stator $\left(22.5^{\circ}\right)$. (c) Normal rotor. (d) Skewed rotor $\left(22.5^{\circ}\right)$.

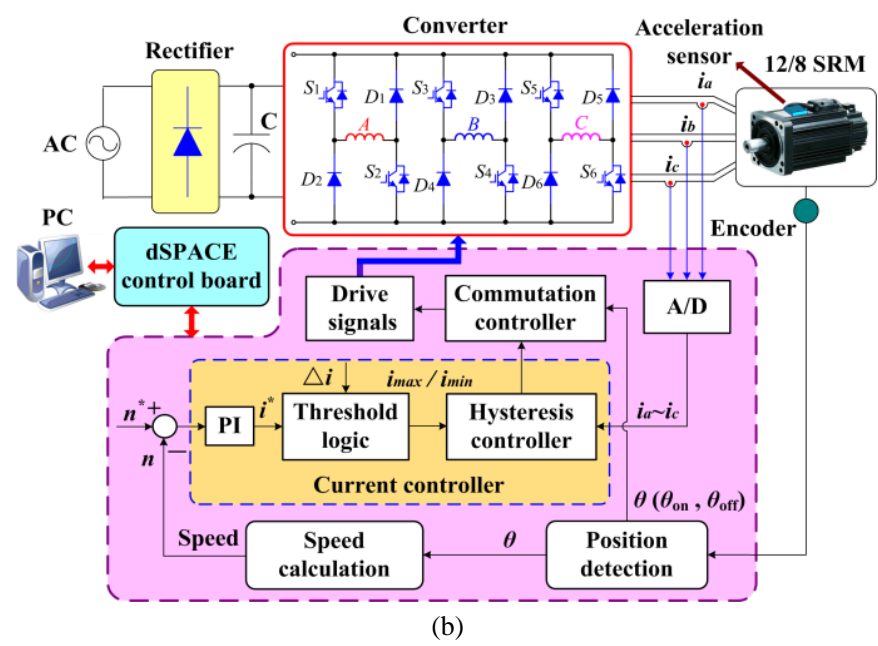

Fig. 14. Schematic diagram of the experimental setup.

The vibration test is performed under the rated load of 0.95 $\mathrm{N} \cdot \mathrm{m}$ and a conducted region of $22.5^{\circ}$. Fig. 15 shows the experimental results for the conventional SRM at a low speed of $300 \mathrm{r} / \mathrm{min}$ and a high speed of $1500 \mathrm{r} / \mathrm{min}$, respectively; where $U_{a}$ is the phase A voltage, $i_{a}$ is the phase A current, $P_{a}$ is the rotor position of phase A, and $V_{i b}$ is the vibration signal of the motor. The turn-on angle is set to $0^{\circ}$ and the turn-off angle to $22.5^{\circ}$. The vibration at the high speed is stronger than that at the low speed. In the case of SR-SRM, the turn-on and turn-off angles are set to $-10.5^{\circ}$ and $12^{\circ}$, respectively, which are both advanced for $10.5^{\circ}$ to ensure a current conduct in the same torque region in accordance with the conventional SRM. As shown in Fig. 16, the vibration level is reduced by 55\% at $300 \mathrm{r} / \mathrm{min}$ and $51 \%$ at $1500 \mathrm{r} / \mathrm{min}$, due to the use of skewed rotor. As to SS-SRM in Fig. 17, the turn-on and turn-off angles are set to $10.5^{\circ}$ and $33^{\circ}$, respectively, which are both set lagged for $10.5^{\circ}$ according to the torque characteristic, and the vibration level is obviously reduced by $65 \%$ at $300 \mathrm{r} / \mathrm{min}$ and $63 \%$ at $1500 \mathrm{r} / \mathrm{min}$, due to the use of the skewed stator. In 


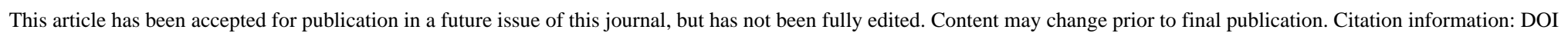
10.1109/TMAG.2015.2441035, IEEE Transactions on Magnetics

\section{IEEE TRANSACTIONS ON MAGNETICS}

terms of SSR-SRM, as shown in Fig. 18, the vibration level is obviously reduced by $68 \%$ at $300 \mathrm{r} / \mathrm{min}$ and $65 \%$ at 1500 $\mathrm{r} / \mathrm{min}$, because of skewing in both the stator and rotor, without the need for turn-on and turn-off angles modulation. It can be seen that the SS-SRM and SSR-SRM both have lower vibration levels than the conventional SRM and SR-SRM at low and high speeds.

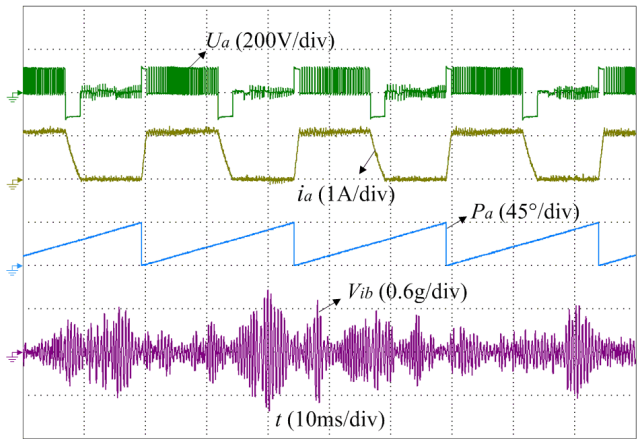

(a)

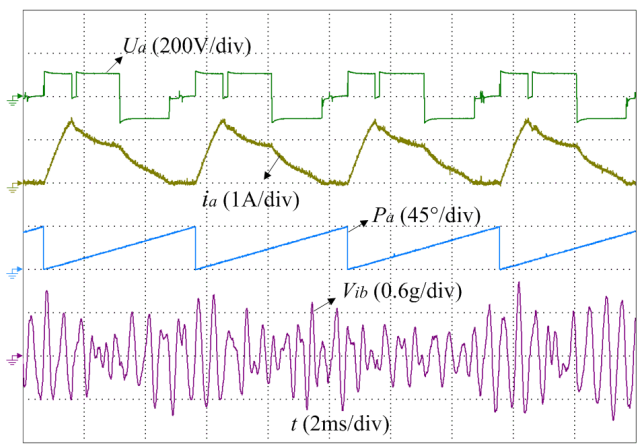

(b)

Fig. 15. Experimental results for conventional SRM. (a) $300 \mathrm{r} / \mathrm{min}$. (b) 1500 $\mathrm{r} / \mathrm{min}$.

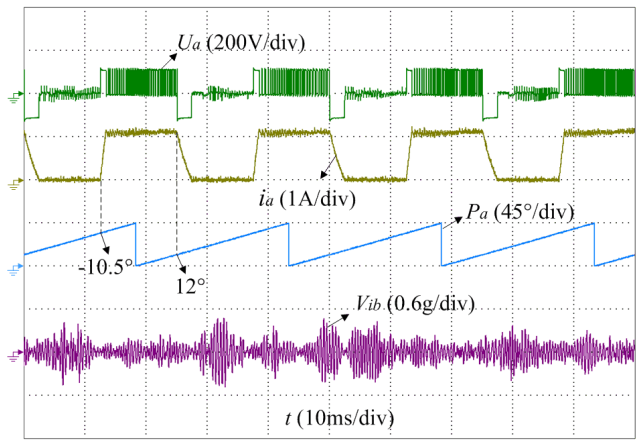

(a)

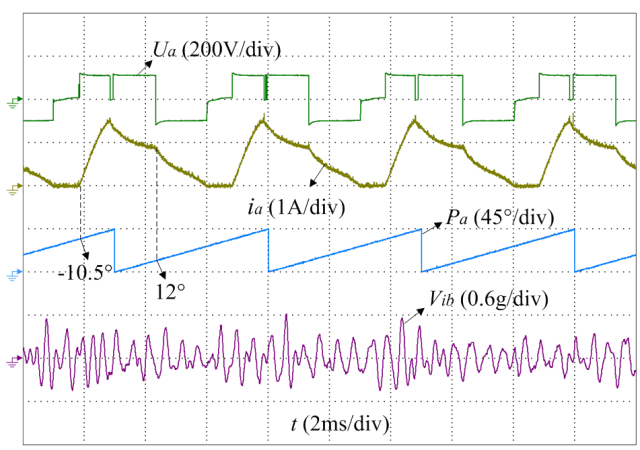

(b)

Fig. 16. Experimental results for SR-SRM. (a) $300 \mathrm{r} / \mathrm{min}$. (b) $1500 \mathrm{r} / \mathrm{min}$.

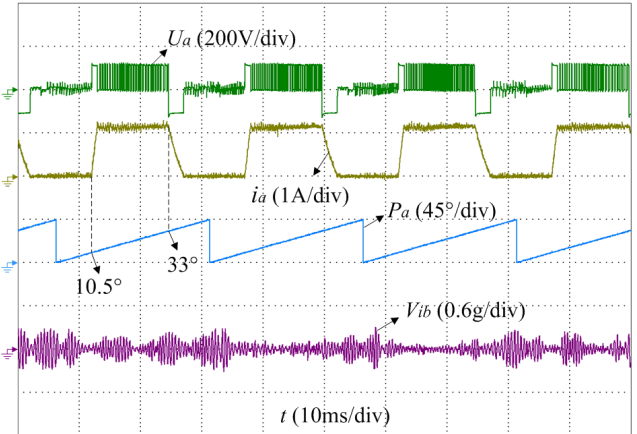

(a)

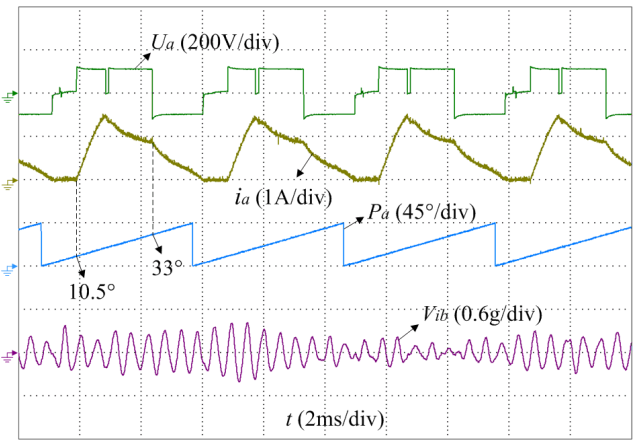

(b)

Fig. 17. Experimental results for SS-SRM. (a) $300 \mathrm{r} / \mathrm{min}$. (b) $1500 \mathrm{r} / \mathrm{min}$.

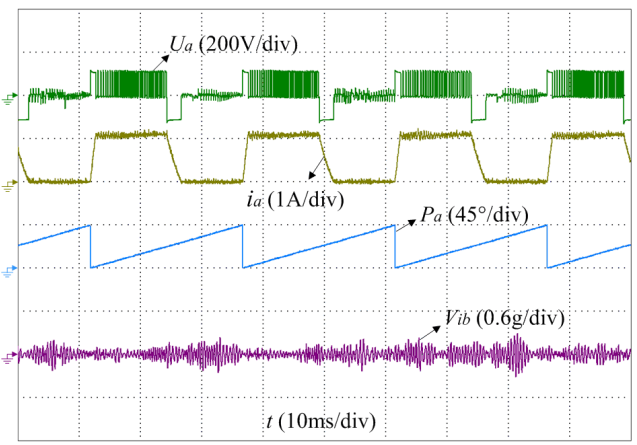

(a)

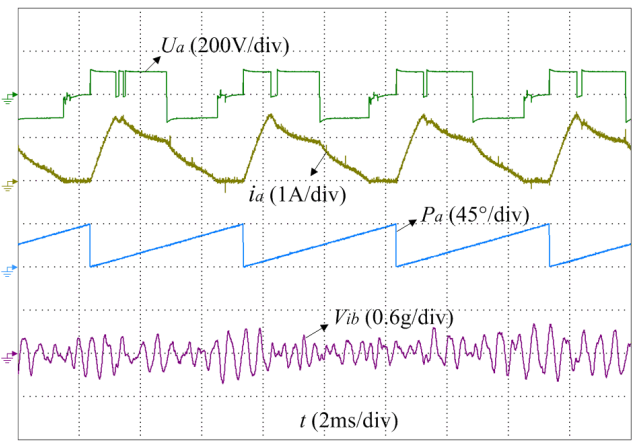

(b)

Fig. 18. Experimental results for SSR-SRM. (a) $300 \mathrm{r} / \mathrm{min}$. (b) $1500 \mathrm{r} / \mathrm{min}$.

Fig. 19 shows a comparison of the torque and efficiency characteristics of the conventional SRM, SR-SRM, SS-SRM and SSR-SRM at different speeds. Clearly, the measured efficiency and torque of SR-SRM fall off obviously and those of SS-SRM drop slightly, compared to the conventional SRM. However, the efficiency and torque of SSR-SRM are almost identical with the conventional SRM. The performance 
comparison of the four motors is summarized in Table II. It can be found that the SS-SRM and SSR-SRM both have lower vibration, higher torque and higher efficiency than the SRSRM. Although skewing the rotor can reduce the motor vibration, its torque and efficiency are also reduced. As a result, this work suggests that skewing the stator is more effective.

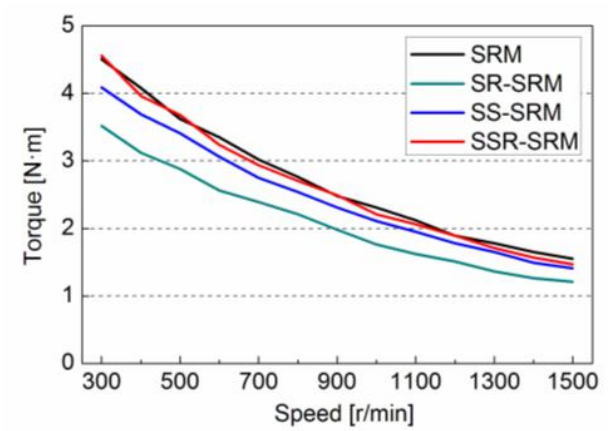

(a)

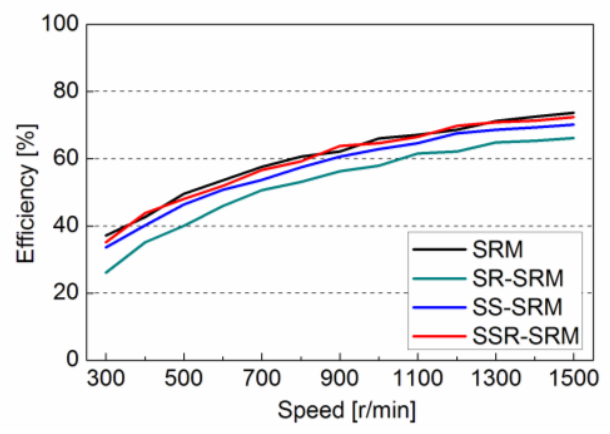

(b)

Fig. 19. Comparisons of the torque and efficiency characteristics. (a) Speedtorque. (b) Speed-efficiency.

TABLE II

COMPARISON OF THE MOTOR PERFORMANCE

\begin{tabular}{ccccc}
\hline \hline Machine & SRM & SR-SRM & SS-SRM & SSR-SRM \\
\hline Vibration & High & Medium & Low & Low \\
Efficiency & High & Low & High & High \\
Torque & High & low & High & High \\
$\begin{array}{c}\text { Angle } \\
\text { modulation }\end{array}$ & No & Yes & Yes & No \\
\hline \hline
\end{tabular}

\section{CONCLUSION}

In this paper, four different three-phase 12/8-pole SRMs including conventional SRM, SS-SRM, SR-SRM and SSRSRM are introduced and designed, to investigate the effect of skewing on the radial vibration force, which is the main source of vibration. The radial forces distributed on the stator yoke under different skewing angles for the skewed motors are compared with the conventional SRM, by establishing a 3$\mathrm{D}$ FEM model in Ansoft. The inductance and torque characteristics are illustrated to show the performance and angle modulation for the three novel motors. The four motors are all designed and fabricated for experimental investigation at low and high speed operations.

From this work, it is found that: 1) Skewing can reduce the vibration of the SRMs and the radial force of SS-SRM, SRSRM and SSR-SRM are all reduced with the skewing angle; 2)
The SS-SRM and SSR-SRM have similar and significantly reduced radial forces than the SRM and SR-SRM; 3) The turnon and turn-off angles of stator currents should be adjusted both advanced for SR-SRM, and both lagged for SS-SRM; 4) The torque and efficiency of SR-SRM are reduced, while the SS-SRM and SSR-SRM can be operated with little reduction in torque and efficiency; 5) It is suggested that skewing the stator is more effective to mitigate the vibration than skewing the rotor in SRMs.

\section{ACKNOWLEDGMENT}

This work was supported in part by the Chinese National 863 program under Project 2011AA11A101, and the National Nature Science Foundation of China under Project 51377139.

\section{REFERENCES}

[1] X. D. Xue, K. W. E. Cheng, T. W. Ng, and N. C. Cheung, "Multiobjective optimization design of in-wheel switched reluctance motors in electric vehicles," IEEE Trans. Ind. Electron., vol. 57, no. 9, pp. 29802987, Sep. 2010.

[2] H. Toda, K. Senda, S. Morimoto, and T. Hiratani, "Influence of various non-oriented electrical steels on motor efficiency and iron loss in switched reluctance motor," IEEE Trans. Magn., vol. 49, no. 7, pp. 3850-3853, Jul. 2013.

[3] C. Gan, J. Wu, S. Yang, and Y. Hu, "Phase current reconstruction of switched reluctance motors from dc-link current under double highfrequency pulses injection," IEEE Trans. Ind. Electron., vol. 62, no. 5, pp. 3265-3276, May 2015.

[4] A. H. Isfahani, and B. Fahimi, "Comparison of mechanical vibration between a double-stator switched reluctance machine and a conventional switched reluctance machine," IEEE Trans. Magn., vol. 50, no. 2, pp. 293-296, Feb. 2014.

[5] L. Dong-Hee, P. Trung Hieu, and A. Jin-Woo, "Design and operation characteristics of four-two pole high-speed SRM for torque ripple reduction," IEEE Trans. Ind. Electron., vol. 60, no. 9, pp. 3637-3643, Sep. 2013.

[6] M. N. Anwar, and I. Husain, "Radial force calculation and acoustic noise prediction in switched reluctance machines," IEEE Trans. Ind. Appl., vol. 36, no. 6, pp. 1589-1597, Nov./Dec. 2000.

[7] I. Husain, A. Radun, and J. Nairus, "Unbalanced force calculation in switched-reluctance machines," IEEE Trans. Magn., vol. 36, no. 1, pp. 330-338, Jan. 2000.

[8] L. Chenjie, and B. Fahimi, "Prediction of radial vibration in switched reluctance machines," IEEE Trans. Energy Convers., vol. 28, no. 4, pp. 1072-1081, Dec. 2013.

[9] L. Chenjie, and B. Fahimi, "Prediction of acoustic noise in switched reluctance motor drives," IEEE Trans. Energy Convers., vol. 29, no. 1, pp. 250-258, Mar. 2014.

[10] L. Jian, S. Xueguan, and C. Yunhyun, "Comparison of 12/8 and 6/4 switched reluctance motor: noise and vibration aspects," IEEE Trans. Magn., vol. 44, no. 11, pp. 4131-4134, Nov. 2008.

[11] L. Feng-Chieh, and Y. Sheng-Ming, "An approach to producing controlled radial force in a switched reluctance motor," IEEE Trans. Ind. Electron., vol. 54, no. 4, pp. 2137-2146, Aug. 2007.

[12] C. Xin, D. Zhiquan, Y. Gang, and W. Xiaolin, "Independent control of average torque and radial force in bearingless switched-reluctance motors with hybrid excitations," IEEE Trans. Power Electron., vol. 24, no. 5, pp. 1376-1385, May 2009.

[13] A. Jin-Woo, P. Sung-Jun, and L. Dong-Hee, "Hybrid excitation of SRM for reduction of vibration and acoustic noise," IEEE Trans. Ind. Electron., vol. 51, no. 2, pp. 374-380, Apr. 2004.

[14] C. Pollock, and W. Chi-Yao, "Acoustic noise cancellation techniques for switched reluctance drives," IEEE Trans. Ind. Appl., vol. 33, no. 2, pp. 477-484, Mar./Apr. 1997.

[15] Z. Q. Zhu, X. Liu, and P. Zaiping, "Analytical model for predicting maximum reduction levels of vibration and noise in switched reluctance machine by active vibration cancellation," IEEE Trans. Energy Convers., vol. 26, no. 1, pp. 36-45, Mar. 2011. 
IEEE TRANSACTIONS ON MAGNETICS

[16] P. O. Rasmussen, J. H. Andreasen, and J. M. Pijanowski, "Structural stator spacers-a solution for noise reduction of switched reluctance motors," IEEE Trans. Ind. Appl., vol. 40, no. 2, pp. 574-581, Mar./Apr. 2004.

[17] L. Jian, and C. Yunhyun, "Investigation into reduction of vibration and acoustic noise in switched reluctance motors in radial force excitation and frame transfer function aspects," IEEE Trans. Magn., vol. 45, no. 10, pp. 4664-4667, Oct. 2009.

[18] L. Yongbin, and C. C. Mi, "Doubly salient permanent-magnet machine with skewed rotor and six-state commutating mode," IEEE Trans. Magn., vol. 43, no. 9, pp. 3623-3629, Sep. 2007.

[19] Y. Zou, K. E. Cheng, N. C. Cheung, and J. Pan, "Deformation and noise mitigation for the linear switched reluctance motor with skewed teeth structure," IEEE Trans. Magn., vol. 50, no. 11, pp. 1-4, Nov. 2014.

[20] Y. Hyong-Yeol, L. Young-Cheol, and K. Hyun-Chul, "Acoustic noise/vibration reduction of a single-phase SRM using skewed stator and rotor," IEEE Trans. Ind. Electron., vol. 60, no. 10, pp. 4292-4300, Oct. 2013.

[21] H. Torkaman, N. Faraji, and M. S. Toulabi, "Influence of rotor structure on fault diagnosis indices in two-phase switched reluctance motors," IEEE Trans. Magn., vol. 50, no. 3, Mar. 2014. 